\title{
Characteristics of Postoperative Pain After VATS and Pain-Related Factors: The Experience in National Cancer Center of China
}

This article was published in the following Dove Press journal: Journal of Pain Research

\section{Yao Tong \\ Peipei Wei \\ Shuang Wang \\ Qiuying Sun \\ Yanzheng Cui \\ Ning Ning \\ Sitong Chen \\ Xin $\mathrm{He}$}

Department of Thoracic Surgery, Cancer Hospital, Chinese Academy of Medical Sciences, Peking Union Medical College, Beijing, People's Republic of China
Correspondence: Xin $\mathrm{He}$ Tel/Fax +86 10-87787/60 Email hexinzlyy@163.com
Purpose: No final conclusion has yet been reached on characteristics of postoperative pain and pain-related factors after video-assisted thoracoscopic surgery (VATS). This study was designed to explore features of acute severe pain and chronic post-surgical pain (CPSP), and the pain-related factors of VATS.

Patients and Methods: Data of patients who underwent VATS for lung cancer in Cancer Hospital, Chinese Academy of Medical Sciences between March 2017 and January 2019 were reviewed in this retrospective study. A numerical rating scale (NRS) was used for evaluating the intensity of postoperative pain including no pain $(\mathrm{NRS}=0)$, mild pain $(\mathrm{NRS}=1-3)$, moderate pain $(\mathrm{NRS}=4-6)$, and severe pain $(\mathrm{NRS}=7-10)$. Pain intensity was assessed daily within a week after operation, and also evaluated at 3 months postoperatively. Results: One hundred and five (3.4\%) of the 3072 patients enrolled experienced severe pain (NRS $=7-10)$ on the 1st day after operation, and 17 (0.6\%) on the 2nd day. Smoking history, three-port VATS, prolonged operation time, and without patient-controlled analgesia (PCA) were correlated to increased incidence of severe pain. Among all patients, 237 (7.7\%) cases generated CPSP, and VATS type, operation time, duration of drainage, and severe pain on the 1st day were four independent risk factors related to CPSP.

Conclusion: Patients seemed to experience a lower incidence of acute severe pain and CPSP after VATS than traditional open surgery. Acute severe pain was correlated with smoking history, VATS type, operation time, and PCA; VATS type, operation time, duration of drainage, and severe pain on the 1st day postoperatively were four independent risk factors of CPSP.

Keywords: VATS, acute severe pain, chronic post-surgical pain, NRS, risk factor

\section{Introduction}

As one of the most common malignant diseases, lung cancer has a high incidence rate and threatens human health and life seriously. ${ }^{1}$ A study reported that the agestandardized incidence rates of lung cancer were from 33.3 to 66.8 per 100,000 among males and 10.5 to 37.4 per 100,000 among females in most of the Americas, Europe, and Oceania populations during the period 2003-2007. ${ }^{2}$ A report from the National Cancer Center of China showed that the crude incidence rate of lung cancer was $54.66 / 100,000$, the age-standardized incidence rates by China population and by World population were $35.13 / 100,000$ and $34.86 / 100,000$, respectively. ${ }^{3}$ Surgical resection is still the most basic and important clinical treatment method at present. $^{4}$ With the development of science and technology, and also with the 
improvement of medical services level, the traditional open thoracotomy has been gradually replaced by videoassisted thoracoscopic surgery (VATS) for resectable lung cancer. ${ }^{5}$ Postoperative acute chest pain which can lead to various adverse outcomes is a head-scratching problem. A large number of studies have focused on postoperative acute pain in order to analyze the characteristics of pain and find treatment strategy. VATS, as the minimally invasive surgery (MIS), may provide patients with the relieved acute pain compared to traditional open surgery in theory. No final conclusion has yet been reached on the characteristics of acute severe pain and pain-related factors after VATS however.

Chronic pain has been recognized as pain that persists past normal healing time, while chronic post-surgical pain (CPSP) is defined as pain that develops after a surgical procedure and persists at least 3 months after surgery, with the exclusion of all other causes of pain (infection, recurring malignancy) as well as pain from a preexisting pain problem. ${ }^{6}$ Patients are likely to complain of a variety of pain symptoms, such as aching, numbness, stabbing, cramping, and burning. Although MIS, the reported CPSP incidence after VATS still ranges from $20 \%$ to $47 \%{ }^{7,9}$ The risk factors related to CPSP have not been clearly established, especially for VATS.

This study was designed for the purpose of exploring the features of pain, including both acute severe pain and CPSP after VATS, and analyzing the related factors of postoperative pain with the aim of receiving better methods to relieve pain for lung cancer patients undergoing VATS.

\section{Patients and Methods}

\section{Patients}

This retrospective study was approved by the Institutional Review Board of National Cancer Center of China, Cancer Hospital, Chinese Academy of Medical Sciences. All subjects or their representatives gave their written informed consent after receiving a full explanation of the nature of the study. This study was conducted in accordance with the Declaration of Helsinki.

Clinical data of patients who underwent VATS for lung cancer in Cancer Hospital, Chinese Academy of Medical Sciences between March 2017 and January 2019 were reviewed and analyzed. All data were collected anonymously and confidentially and all procedures were in compliance with the Declaration of Helsinki. This retrospective study was approved by the Institutional Review Board of National Cancer Center of China, Cancer Hospital, Chinese Academy of Medical Sciences. Exclusion criteria included being younger than 18-year old, suffering long-term chronic pain before operation, open surgery, reoperation after VATS, and tumor recurrence during the follow-up period.

\section{Operation}

VATS procedure was performed for all of the persons recruited. Operation types of lobectomy, segmentectomy, and wedge resection were included in this study, and total pneumonectomy was excluded. The procedures of singleport or three-port VATS were performed by 12 experienced surgeons, and intravenous patient-controlled analgesia (PCA) with opioids was administered to patients whose consent had been obtained before surgery.

\section{Evaluation of Pain}

A numerical rating scale $(\mathrm{NRS}=0-10)$ was used for evaluating the intensity of postoperative pain. The pain intensity scale was categorized as no pain $(\mathrm{NRS}=0)$, mild pain $(\mathrm{NRS}=1-3)$, moderate pain $(\mathrm{NRS}=4-6)$, and severe pain $(\mathrm{NRS}=7-10)$. The patients were requested to report the pain intensity twice on the 1st, $2 \mathrm{nd}$, and 3rd day after operation (at 9 am and $3 \mathrm{pm}$ ), the most serious pain (when coughing, moving, rest or others) was collected and the mean score was used as the pain intensity indicator for analyzing for each day, then the pain intensity was recorded as no, mild, moderate, or severe according to the average NRS score. On the 4 th to 7 th days, the pain intensity was evaluated once (9 am) per day; telephone follow-up was used if the patients were discharged within 1 week. The pain intensity was assessed at 3 months after operation during the follow-up period.

\section{Definition of CPSP}

We defined CPSP similarly to Macrae: ${ }^{10}$ 1) Pain that developed after surgery. 2) Other causes for the pain should had been excluded (eg, continuing malignancy or chronic infection). 3) Exacerbation of a pre-existing problem as a cause for the pain had been ruled out. 4) The duration of pain was more than 3 months, and the NRS $\geq 3$. The highest intensity (when coughing, moving, or others) which was evaluated as the chronic pain intensity was collected for analyzing. 


\section{Treatment Strategy of Postoperative Pain}

For patients having PCA, intravenous analgesics were selected for those with severe pain (NRS=7-10); for patients without PCA, intravenous analgesics including Parecoxib Sodium or Flurbiprofen Axetil was routinely provided within 2 days after operation. Oxycodone and Acetaminophen tablets for oral administration were available for patients during late hospitalization.

\section{Statistical Analysis}

SPSS 16.0 (IBM, Chicago, IL, USA) was used for data analysis. Quantitative variables were analyzed with the Student $t$-test according to data distribution (age, BMI, operation time in Table 1; age, BMI, operation time and duration of drainage in Table 2). Categorical variables were analyzed by Chi-square test or Fisher exact test, as appropriate. A $P$-value less than 0.05 was considered significant. Univariate analyses were performed to identify risk factors predicting severe pain and CPSP. Multivariable logistic regression was used to identify the independent factors of CPSP. After univariate analyses, variables including patient's general conditions and operationrelated outcomes with a $P$-value less than 0.05 were included in a multivariable logistic regression model.

Table I Comparisons Between Patients with and without Severe Pain on Ist Day After Operation

\begin{tabular}{|l|l|l|l|}
\hline Parameters & $\begin{array}{l}\text { Severe } \\
\text { Pain } \\
\text { (NRS } \geq 7)\end{array}$ & $\begin{array}{l}\text { No-Severe } \\
\text { Pain } \\
\text { (NRS<7) }\end{array}$ & P-value \\
\hline Gender (male/female), cases & $33 / 72$ & $1134 / 1833$ & 0.159 \\
\hline Age, years & $57.2 \pm 9.8$ & $56.8 \pm 11.7$ & 0.746 \\
\hline BMI, Kg/m ${ }^{2}$ & $25.5 \pm 2.7$ & $25.9 \pm 3.2$ & 0.280 \\
\hline $\begin{array}{l}\text { Smoking before operation (yes/ } \\
\text { no), cases }\end{array}$ & $69 / 36$ & $1435 / 1532$ & $<0.001$ \\
\hline $\begin{array}{l}\text { VATS type (single-port/three-port), } \\
\text { cases }\end{array}$ & $15 / 90$ & $2421 / 546$ & $<0.001$ \\
\hline $\begin{array}{l}\text { Operation type (lobectomy/ } \\
\text { segmentectomy/wedge resection), } \\
\text { cases }\end{array}$ & $63 / 19 / 23$ & $1959 / 560 / 448$ & 0.247 \\
\hline Operation time, min & $139.2 \pm 20.5$ & $133.4 \pm 24.2$ & 0.015 \\
\hline Surgical site (left/right), cases & $36 / 69$ & $1071 / 1896$ & 0.704 \\
\hline Number of chest tube (1/2), cases & $103 / 2$ & $2919 / 48$ & 0.819 \\
\hline PCA (yes/no), cases & $60 / 45$ & $2069 / 898$ & 0.006 \\
\hline
\end{tabular}

Abbreviations: BMI, body mass index; NRS, numerical rating scale; PCA, patientcontrolled analgesia.
Table 2 Comparisons Between Patients with and without CPSP

\begin{tabular}{|l|l|l|l|}
\hline Parameters & CPSP & No-CPSP & P-value \\
\hline Gender (male/female), cases & $73 / 164$ & $1094 / 1741$ & 0.018 \\
\hline Age, years & $55.7 \pm 10.8$ & $56.9 \pm 11.7$ & 0.112 \\
\hline BMI, Kg/m & $26.0 \pm 2.7$ & $25.9 \pm 3.3$ & 0.675 \\
\hline $\begin{array}{l}\text { Smoking before operation (yes/no), } \\
\text { cases }\end{array}$ & $143 / 94$ & $1361 / 1474$ & $<0.001$ \\
\hline $\begin{array}{l}\text { VATS type (single-port/three-port), } \\
\text { cases }\end{array}$ & $37 / 200$ & $2399 / 436$ & $<0.001$ \\
\hline $\begin{array}{l}\text { Operation type (lobectomy/ } \\
\text { segmentectomy/wedge resection), } \\
\text { cases }\end{array}$ & $147 / 54 / 36$ & $1875 / 525 /$ & 0.262 \\
\hline Operation time, min & 435 & 0.955 \\
\hline Surgical site (left/right), cases & $85 / 152$ & $1022 / 1813$ & 0.541 \\
\hline Number of chest tube (I/2), cases & $232 / 5$ & $2790 / 45$ & 0.001 \\
\hline Duration of drainage, days & $3.7 \pm 0.7$ & $3.4 \pm 0.8$ & $<0.001$ \\
\hline
\end{tabular}

Abbreviations: BMI, body mass index; CPSP, chronic post-surgical pain; VATS, video-assisted thoracoscopic surgery.

\section{Results}

A total of 3072 patients were collected for analyzing in this study. Of these patients, 1167 (38\%) were male and 1905 (62\%) were female; age ranged from 28 to 75 years, with an average of $56.8 \pm 11.7$ years old; 1504 (49.0\%) patients had a smoking history before operation. Lobectomy, segmentectomy, and wedge resection were performed for $2022(65.8 \%), 579(18.8 \%)$, and 471 $(15.3 \%)$ patients, respectively. Non-small cell lung cancer was confirmed for all patients by postoperative pathology. Single-port VATS was conducted in 2436 (79.3\%) patients and three-port VATS in $636(20.7 \%)$ patients. A total of $3022(98.4 \%)$ patients had one chest tube and $50(1.6 \%)$ had two tubes after operation, and the retention time of the chest tube was from 2 to 5 days.

The mean NRS score decreased with the passage of time, the change was shown in Figure 1. One hundred and five (3.4\%) and $17(0.6 \%)$ patients experienced severe pain on the 1st and 2nd day after operation, respectively (Figure 2). As shown in Table 1, some factors were related to the acute severe pain on the 1st day postoperatively, smoking history was related to a higher incidence of severe pain, while threeport VATS, prolonged operation time, and being without PCA could also lead to increased incidence of severe pain.

The incidence of CPSP was $7.7 \%$ (237 cases) in this study. As shown in Table 2, the risk factors related to CPSP included female patients, having smoking history, 
Change of pain intensity within the first week after operation

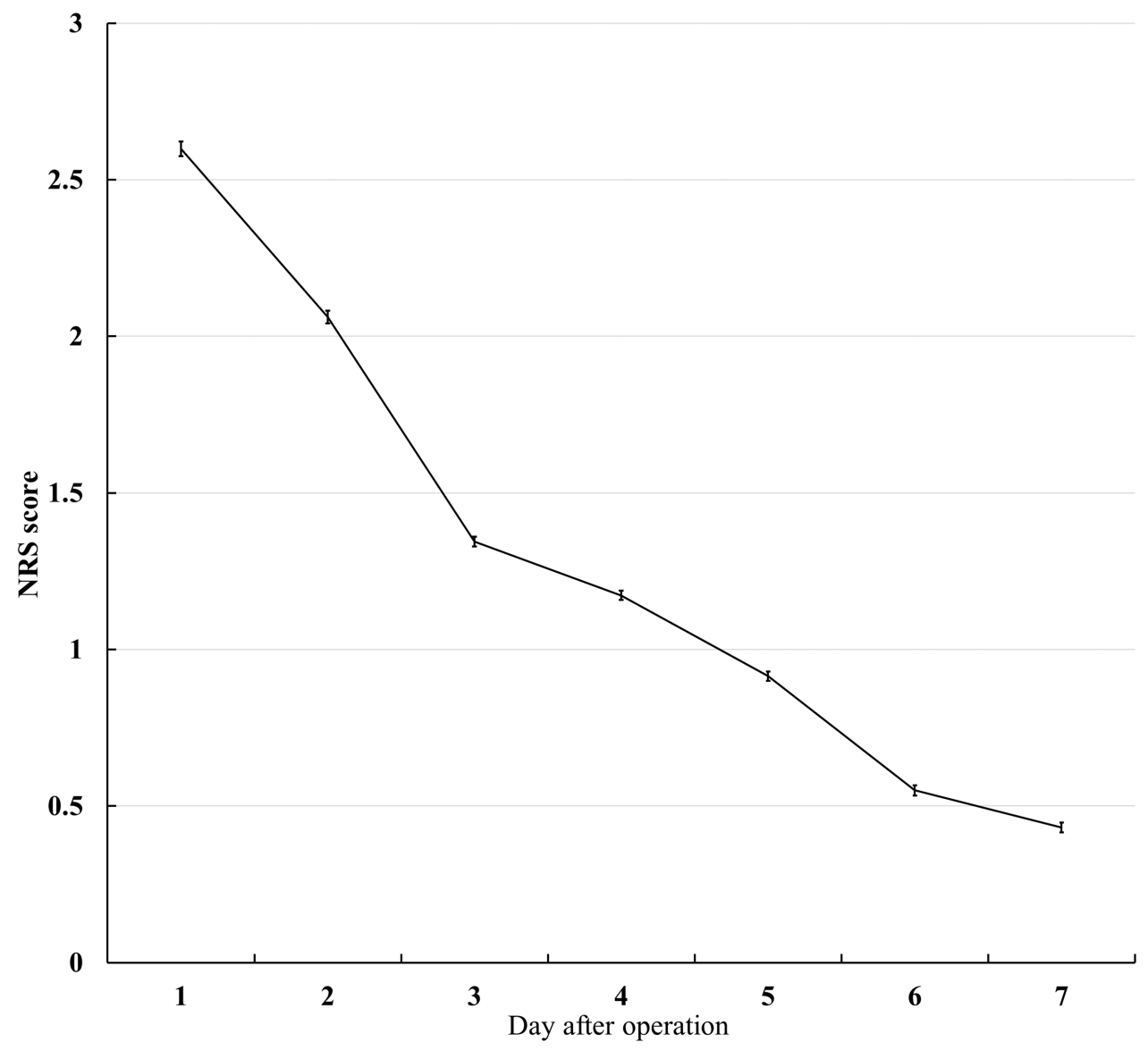

Figure I The change of mean NRS (numerical rating scale) scores from the Ist to the 7th day postoperatively.

three-port VATS surgery, longer operation time, and prolonged duration of drainage. We also found that severe pain on the 1 st and 2 nd day after operation was closely related to CPSP (Table 3), $81.9 \%$ and $88.2 \%$ of patients with acute severe pain on the 1 st and 2 nd day developed CPSP, respectively.

Table 4 illustrated that VATS type, operation time, duration of drainage, and severe pain on the 1st day were four independent risk factors related to CPSP.

\section{Discussion}

VATS has become a selected operation type during recent years. Without compromising short-term and long-term outcomes, VATS can provide several benefits to patients compared with traditional open thoracotomy. ${ }^{11}$ Postsurgical pain is one of the most common surgical complications, despite the advances in understanding pain and the development of new modalities for pain management. ${ }^{12}$ Several studies demonstrate that $41-69 \%$ of patients have experienced moderate-to-severe pain after operation. ${ }^{13,14}$
Whether VATS can reduce the pain intensity or not is still uncertain.

Data of 312 patients who received open thoracotomy or VATS were analyzed in a recent study designed by Wang et al, ${ }^{7}$ their results conveyed that the pain intensity was $3.91 \pm 2.12$ at rest and $5.73 \pm 2.26$ when moving in the VATS group on the 1 st day after operation, and both of them were higher than in the open group. Whereas a study designed by Wildgaard et $\mathrm{al}^{15}$ gave the opposite results; their study confirmed that patients who underwent VATS had decreased pain intensity during the first 72 hours. In our study, the mean NRS scores were 2.60 $\pm 1.31,2.06 \pm 1.11$, and $1.34 \pm 0.88$ on the $1 \mathrm{st}, 2 \mathrm{nd}$, and $3 \mathrm{rd}$ day after operation, and the incidence of severe pain was $3.4 \%$ and $0.6 \%$ during the first 2 days. No patients experienced severe pain on the 3rd day after operation.

We also employed further analysis about the high-risk factors related to severe pain, and the results showed that patients with a smoking history had a high incidence of severe pain. Maybe smoking before the operation lead to a bad cough and the cough induced serious pain. Single-port 


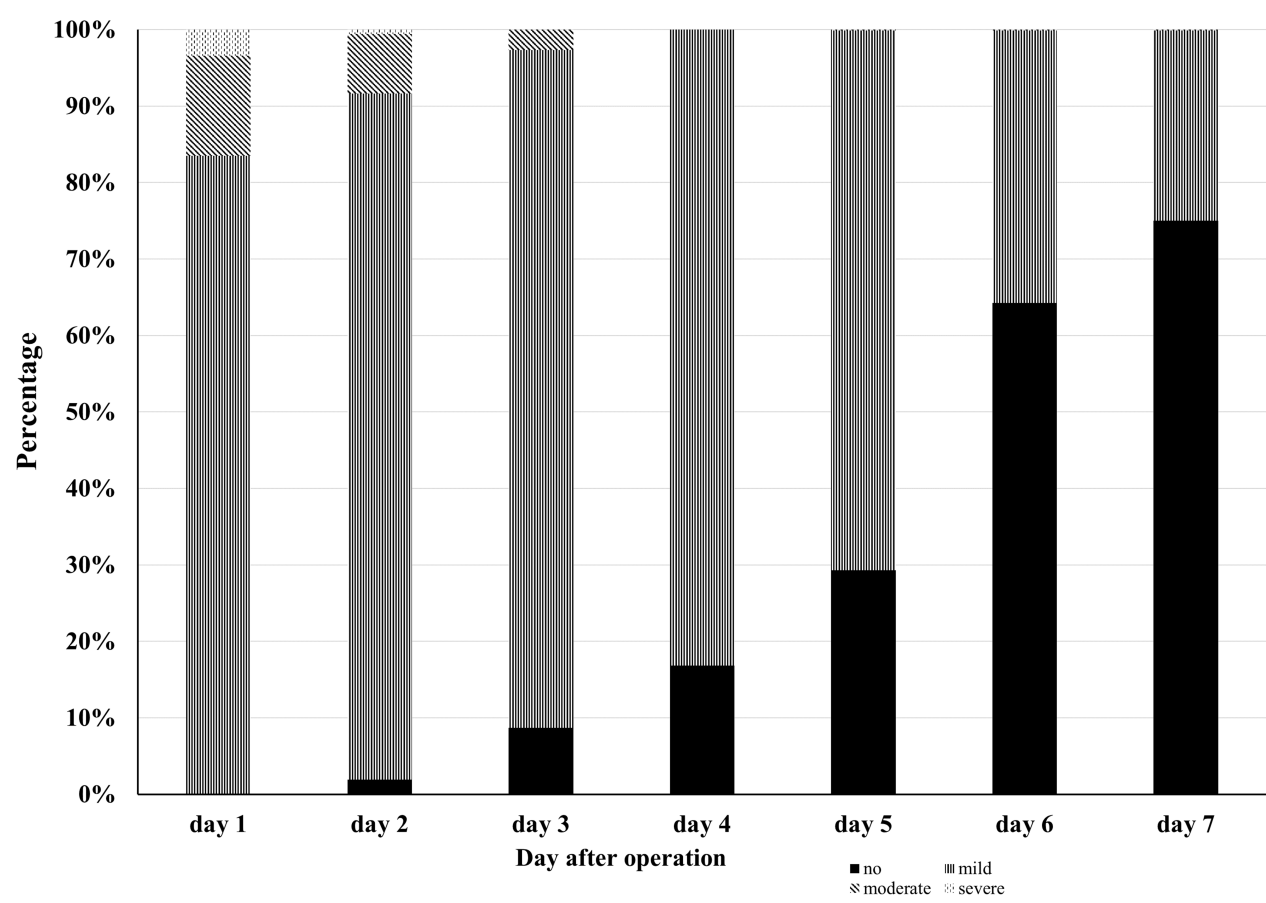

Figure 2 The different percentages for each pain intensity within the first week after operation.

VATS contributed to a lower incidence of severe pain compared with three-port VATS in our study, which was similar to previous results by Sun et al. ${ }^{16}$ Their results demonstrated that increased BMI, smoking history, and multi-port VATS had high incidence of moderate-severe pain during the first 24 hours after operation. There was another study which illustrated that besides pain intensity, the functional areas such as physical function, role function, emotional function, social function, and the overall health status of the patients with single-port were significantly better than those with three-port. ${ }^{6}$ PCA had ideal analgesic effect, patients with PCA had lower incidence of severe pain after operation.

Table 3 Univariate Analyses for the Relationship Between Severe Pain and CPSP

\begin{tabular}{|l|l|l|l|}
\hline $\begin{array}{l}\text { Pain Intensity After } \\
\text { Operation }\end{array}$ & $\begin{array}{l}\text { CPSP } \\
(\mathbf{n = 2 3 7 )}\end{array}$ & $\begin{array}{l}\text { No-CPSP } \\
(\mathbf{n = 2 8 3 5 )}\end{array}$ & P-value \\
\hline $\begin{array}{l}\text { Severe pain on the } \\
\text { Ist day, cases } \\
\text { Yes } \\
\text { No }\end{array}$ & 86 & 19 & $<0.001$ \\
\hline $\begin{array}{l}\text { Severe pain on the } \\
\text { 2nd day, cases } \\
\text { Yes }\end{array}$ & 151 & 2816 & \\
No & 15 & 2 & $<0.001$ \\
\hline
\end{tabular}

Abbreviation: CPSP, chronic post-surgical pain.
CPSP was defined initially by Macrae and Davies ${ }^{8}$ as a persistent pain which has existed for a minimum of 2 months following a surgical procedure. There are many suggestions to revise this definition by the International Association of Pain Study (IAPS). Currently, 3 months is considered the minimal accepted duration to diagnose a patient with CPSP. CPSP places considerable physical and psychological burdens on individuals. An early study on CPSP reported that $22.5 \%$ of 5130 chronic pain patients seen in 10 UK clinics indicated major surgery as its source. ${ }^{17}$ Since then, studies have specified that the incidence of CPSP ranged from $10 \%$ to $70 \%$ depending on the surgery types. ${ }^{18,19}$ Wang et $\mathrm{al}^{20}$ reported that $64.5 \%$

Table 4 Logistic Regression Analysis for the Independent Factors of CPSP

\begin{tabular}{|l|l|l|l|l|}
\hline \multirow{2}{*}{ Related Factors } & \multicolumn{4}{|l|}{ Incidence of CPSP } \\
\cline { 2 - 5 } & $\mathbf{R R}$ & $\mathbf{9 5 \%} \mathbf{~ C ~}$ & P-value \\
\hline Gender & 1.352 & 0.940 & 1.945 & 0.103 \\
Smoking before operation & 1.282 & 0.911 & 1.806 & 0.154 \\
VATS type & 4.536 & 3.736 & 5.508 & $<0.001$ \\
Operation time & 1.008 & 1.001 & 1.016 & 0.024 \\
Duration of drainage & 1.372 & 1.108 & 1.697 & 0.004 \\
Severe pain on Ist day & 25.825 & 13.448 & 49.593 & $<0.001$ \\
Severe pain on 2nd day & 3.080 & 0.464 & 20.449 & 0.244 \\
\hline
\end{tabular}

Abbreviations: CPSP, chronic post-surgical pain; VATS, video-assisted thoracoscopic surgery. 
of patients who underwent thoracotomy experienced CPSP, and Peng et $\mathrm{al}^{6}$ reported that $24.9 \%$ of patients who underwent open and VATS thoracotomy generated CPSP. Reported incidence of CPSP after VATS ranged from $13.3 \%$ to $47 \%$, ${ }^{21}$ and the incidence of CPSP was $7.7 \%$ in our study. We thought that removing patients with chronic pain history from this study might be a critical reason for the lower incidence of CPSP.

Several operation-related factors have an influence on CPSP, Peng et $\mathrm{al}^{6}$ reported that age $<60$ years old, female gender, and prolonged duration of postoperative chest tube drainage ( $\geq 4$ days) were related to a high incidence of CPSP. Bayman ${ }^{21}$ reported that severity of acute pain was associated with chronic pain after thoracic surgery. Buchheit $^{22}$ reported that prolonged duration of chest tube drainage had an increased incidence of CPSP. Our results demonstrated that female patients, smoking history, threeport VATS, longer operation time, and prolonged duration of drainage were correlated to the high incidence of CPSP, meanwhile, we found that patients who experienced severe pain during the first 2 days postoperatively had a higher chance to experience CPSP. VATS type, operation time, duration of drainage, and severe pain on the 1st day were four independent risk factors for high incidence of CPSP.

The shortcomings of the study were that no open surgery data was collected and analyzed, so we could not compare the differences including characteristics of acute pain and CPSP, and influence factors between open surgery and VATS.

\section{Conclusion}

VATS seems to have lower incidence of acute severe pain and CPSP, with smoking history, VATS type, operation time, and PCA being related to acute severe pain; VATS type, operation time, duration of drainage, and severe pain on the 1 st day postoperatively are independent risk factors of CPSP.

\section{Acknowledgments}

The authors thank Zhang $\mathrm{Na}$ for supporting data, her support is the key factor for completion of this manuscript.

\section{Disclosure}

The authors report no conflicts of interest in this work.

\section{References}

1. Singal G, Miller PG, Agarwala V, et al. Association of patient characteristics and tumor genomics with clinical outcomes among patients with non-small cell lung cancer using a clinicogenomic database. JAMA. 2019;321(14):1391-1399. doi:10.1001/jama.2019.3241

2. Zhang Y, Ren JS, Huang HY, et al. International trends in lung cancer incidence from 1973 to 2007. Cancer Med. 2018;7(4):1479-1489.
3. Liu S, Chen Q, Guo L, et al. Incidence and mortality of lung cancer in China, 2008-2012. Chin J Cancer Res. 2018;30(6):580-587. doi:10.21147/j.issn.1000-9604.2018.06.02

4. Yang CJ, Kumar A, Klapper JA, et al. A national analysis of long-term survival following thoracoscopic versus open lobectomy for stage I non-small-cell lung cancer. Ann Surg. 2019;269 (1):163-171. doi:10.1097/SLA.0000000000002342

5. Yang HX, Woo KM, Sima CS, et al. Long-term survival based on the surgical approach to lobectomy for clinical stage I nonsmall cell lung cancer: comparison of robotic, video-assisted thoracic surgery, and thoracotomy lobectomy. Ann Surg. 2017;265(2):431-437. doi:10.1097/SLA.0000000000001708

6. Peng Z, Li H, Zhang C, Qian X, Feng Z, Zhu S. A retrospective study of chronic post-surgical pain following thoracic surgery: prevalence, risk factors, incidence of neuropathic component, and impact on qualify of life. PLoS One. 2014;9(2):e90014. doi:10.1371/journal. pone.0090014

7. Wang H, Li S, Liang N, Liu W, Liu H, Liu H. Postoperative pain experiences in Chinese adult patients after thoracotomy and video-assisted thoracic surgery. J Clin Nurs. 2017;26(17-18):27442754. doi: $10.1111 /$ jocn. 13789

8. Tawfic Q, Kumar K, Pirani Z, Armstrong K. Prevention of chronic post-surgical pain: the importance of early identification of risk factors. J Anesth. 2017;31(3):424-431. doi:10.1007/s00540-0172339-x

9. Weinrib AZ, Azam MA, Birnie KA, Burns LC, Clarke H, Katz J. The psychology of chronic post-surgical pain: new frontiers in risk factor identification, prevention and management. Br J Pain. 2017;11 (4):169-177. doi:10.1177/2049463717720636

10. Macrae WA. Chronic pain after surgery. Br J Anaesth. 2001;87 (1):88-98. doi:10.1093/bja/87.1.88

11. Wolff HB, Alberts L, van der Linden N, et al. Cost-effectiveness of stereotactic body radiation therapy versus video assisted thoracic surgery in medically operable stage I non-small cell lung cancer: a modeling study. Lung Cancer. 2020;141:89-96. doi:10.1016/j. lungcan.2020.01.011

12. Usichenko TI, Rottenbacher I, Kohlmann T, et al. Implementation of the quality management system improves postoperative pain treatment: a prospective pre-/post-interventional questionnaire study. $\mathrm{Br}$ $J$ Anaesth. 2013;110(1):87-95. doi:10.1093/bja/aes352

13. Gan TJ, Habib AS, Miller TE, White W, Apfelbaum JL. Incidence, patient satisfaction, and perceptions of post-surgical pain: results from a US national survey. Curr Med Res Opin. 2014;30 (1):149-160. doi:10.1185/03007995.2013.860019

14. Sommer M, de Rijke JM, van Kleef M, et al. The prevalence of postoperative pain in a sample of 1490 surgical inpatients. Eur $J$ Anaesthesiol. 2008;25(4):267-274. doi:10.1017/S026502150700 3031

15. Wildgaard K, Ravn J, Kehlet H. Chronic post-thoracotomy pain: a critical review of pathogenic mechanisms and strategies for prevention. Eur J Cardiothorac Surg. 2009;36(1):170-180. doi:10.1016/j.ejcts.2009.02.005

16. Sun K, Liu D, Chen J, et al. Moderate-severe postoperative pain in patients undergoing video-assisted thoracoscopic surgery: a retrospective study. Sci Rep. 2020;10(1):795. doi:10.1038/s41598020-57620-8

17. Crombie IK, Davies HT, Macrae WA. Cut and thrust: antecedent surgery and trauma among patients attending a chronic pain clinic. Pain. 1998;76(1-2):167-171. doi:10.1016/S0304-3959(98) 00038-4

18. Katz J, Seltzer Z. Transition from acute to chronic postsurgical pain: risk factors and protective factors. Expert Rev Neurother. 2009;9 (5):723-744. doi:10.1586/ern.09.20

19. Kehlet H, Jensen TS, Woolf CJ. Persistent postsurgical pain: risk factors and prevention. Lancet. 2006;367(9522):1618-1625. doi:10. 1016/S0140-6736(06)68700-X 
20. Wang HT, Liu W, Luo AL, Ma C, Huang YG. Prevalence and risk factors of chronic post-thoracotomy pain in Chinese patients from Peking Union Medical College Hospital. Chin Med J. 2012;125 (17):3033-3038.

21. Bayman EO, Parekh KR, Keech J, Selte A, Brennan TJ. A prospective study of chronic pain after thoracic surgery. Anesthesiology. 2017;126 (5):938-951. doi:10.1097/ALN.0000000000001576
22. Buchheit T, Pyati S. Prevention of chronic pain after surgical nerve injury: amputation and thoracotomy. Surg Clin North Am. 2012;92 (2):393-407, x. doi:10.1016/j.suc.2012.01.005

\section{Publish your work in this journal}

The Journal of Pain Research is an international, peer reviewed, open access, online journal that welcomes laboratory and clinical findings in the fields of pain research and the prevention and management of pain. Original research, reviews, symposium reports, hypothesis formation and commentaries are all considered for publication. The manuscript

Submit your manuscript here: https://www.dovepress.com/journal-of-pain-research-journa management system is completely online and includes a very quick and fair peer-review system, which is all easy to use. Visit http:// www.dovepress.com/testimonials.php to read real quotes from published authors. 